\title{
NUMBERING NORMAL
}

\section{Waking up different}

In 1998, thousands of men and women in the United States woke up and found themselves changed. These individuals may have felt the same as they did the day before. They may have got out of bed, showered, made breakfast and driven to work as if it were any other day. Yet overnight they had become overweight. Some had become obese, others morbidly so. Still more had moved from the underweight category to become 'normal'. What kind of drastic vicissitudes had been realised to change so many bodies so rapidly? A sudden increase in nocturnal sleep-related eating disorders? Icing sugar falling like snow from the night sky? No: the National Institutes of Health (NIH) had changed the way the way that it measured Body Mass Index (BMI).

Previously the United States had classified men with a BMI of 27.8 or above and women with a BMI of 27.3 or above as overweight. However, in 1998 it shifted the measurement down to 25 , to fall in line with the World Health Organization's (WHO) standardised classification system and to allow for easier calculability. ${ }^{1}$ In one fell swoop thousands more people in the US were obese. The media responded with panicked commentary about the obesity epidemic, without mentioning the artificial inflation of these new statistics. But why would they? It is perfectly natural to trust in the classification systems of scientists. Yet this example demonstrates that the thresholds of normalcy that we rely on for the classification of health are more fluid that we might imagine. In this book I argue that our bodies have been changed by measurement technology. Our capabilities and parameters have been defined so that we - you shift from states of normalcy to disability at the whim of mercurial thresholds.

Disability history fascinates because it forces us to ask questions about our universal lived experience and how we ascribe meaning and significance to certain attributes and values. What should we be capable of? 
What matters to us? Would these things have mattered in the same way to those living a hundred or so years ago? Does this change anything about how we feel? Such questions are, of course, subject to diversity of experience. Yet the need to standardise and objectify levels of disability using measurement technologies is often in opposition with individual variance. Measuring normalcy has never been simple. The choice of certain measurement systems was influenced by the relative difficulty or ease of their implementation. Subsequently, these chosen measurement classifications have had a crucial impact on our concept of disability, and I show here that these processes were perpetuated and perfected in the interwar years in Britain. This book thus provides a new perspective on the relationship between the measurement and understanding of disability.

The central thesis of this book is that health measurements are given artificial authority if they are particularly amenable to calculability and easy measurement. Furthermore, the selection of people we have chosen to measure as standard is subject to discrimination and bias as we prioritise the measurement of easily recognisable groups. This, I contend, has led to biased data sets that have conflicted with individual perceptions of health, especially in cases of invisible but experiential disability. The real-world consequences of this are highlighted in cases of invisible disability that have been contested, for instance in compensation procedures. Difficulties around diagnosis are compounded by invisible experiences, and so measurement tools are used to make the invisible visible. However, problems often coalesce around felt experiences that do not lend themselves to easy quantification. Dissonance between objective measurement and subjective experience is therefore a recurring theme, resounding in each chapter of this book. Measurement technologies were a crucial component of the drive to quantify bodily norms and grade sensorial symptoms and are thus an important but unrecognised area for the historical investigation of disability.

The historical technologies I am primarily concerned with here relate to the measurement of hearing and breathing. However, I am not providing a history of the modern fields of audiometry or spirometry. ${ }^{2}$ Rather, I aim to reveal the data gaps in these fields. In the book Invisible Women: Exposing Data Bias in a World Designed for Men, feminist activist Caroline Criado Perez coined the phrase 'Henry Higgins Effect', to describe the data gap that leads to technologies designed as neutral really only being suitable for the neutral male. ${ }^{3}$ Examples of this are legion, ranging from mildly inconvenient to dangerous (offices too cold, phones too large, loads too heavy), to fatal (ineffective drugs, unrecognised symptoms, fatal car accidents). Why is this happening? To take the example of fatal car accidents, Perez explains that: 
Men are more likely than women to be involved in a car crash, which means they dominate the numbers of those seriously injured in car accidents. But when a woman is involved in a car crash, she is $47 \%$ more likely to be seriously injured than a man, and $71 \%$ more likely to be moderately injured, even when researchers control for factors such as height, weight, seat-belt usage, and crash intensity. She is also $17 \%$ more likely to die. And it's all to do with how the car is designed - and for whom. ${ }^{4}$

These dire statistics are reflective of the fact that women's (on average) shorter torsos and legs mean that they sit further forward while driving; a 'wilful deviation from the norm' which corresponds to increased internal injuries in front-facing collisions. ${ }^{5}$ Using only data related to men's bodies means that the average is biased towards a male driver. However, it is often only this data that is available and this, of course, is related to ease of measurement. Specifically, the fact that women are regarded as more expensive and difficult to measure, primarily due to the perceived unpredictability of hormonal fluctuations. ${ }^{6}$ Perez explains, 'Female bodies (both the human and animal variety) are, it is argued, too complex, too variable, too costly to be tested on." And yet, Perez's central argument - that we need more research on sex differences to take women's bodies and experiences into account - shows a startling degree of historical naivety about the reasons why we have in the past chosen to measure certain bodies and not others. It is the project of this book to outline the complex historical circumstances and contingencies which have led to the prioritisation of particular measurements of particular kinds. In doing so, I reveal the political expediencies often hidden in the construction of measurement instruments and explicate the potential negative consequences of essentialising social groups as distinct kinds to be categorised for measurement. As Steven Epstein has pointed out, 'Recent reformers assume that a medical insistence on difference necessarily advances the interest of historically disadvantaged groups; but the old medical theories of group difference had just the opposite effect, reinforcing oppression and helping them to consolidate the very disadvantages that we now hope to overturn.8 Angela Saini has also warned of the 'ugly and dangerous history' of research into sex differences. ${ }^{9}$ Moreover, measuring only the ' $70 \mathrm{~kg}$ white man' as a representative average has further, entirely unexplored implications for the understanding of disability.

Disability data gaps can be similarly distorting of normal capabilities. Such omissions are evident in the data sets used in the nascent field of audiometry during the interwar period. Data sets which excluded those with imperfect hearing meant that the average threshold, which represented normalcy, was distorted. Thus, the line of normalcy was artificially high, and the range of those categorised as deaf was too broad. As we will see in Chapter 3, this was 
because these data sets came from telephone companies who needed a minimum efficiency standard for their male customer base. Economic imperatives generated these data, not medical considerations. And, as scientist Dr Phyllis Margaret Tookey Kerridge (1901-1940) pointed out as early as 1937 while using these standards to measure hearing in a medical context, it was an assumption that hearing was universal, with no variation within the normal between groups, such as children. ${ }^{10}$

Within spirometric studies the situation was more complex. The idea that we are all breathing the same air in the same way was problematised from the beginning of spirometry. Data sets were specifically constructed around appropriate reference classes. I use the term reference classes throughout this book to refer to the categories of difference such as race, sex, age, weight, height and class which are variously employed to both produce of knowledge about our health and to validate our social classification systems. For example, sociologist Janet Shim illuminates the fact that the epidemiology of heart disease 'both emerges out of and contributes to systems of social classification by race, class, sex, and gender. ${ }^{11}$

However, the selection of these groups or reference classes was contested and variable throughout the twentieth century. Indeed, the selection of easily recognisable groups promoted the idea of normalcy within certain social groups. This had drastic consequences in impeding the availability of occupational compensation for respiratory disability. Conversely but perhaps equally tragically, the failure to use such reference classes for apparently biological groups (such as women) meant that our understanding of what it meant for women to breathe normally was also misrepresented. The historical use of these reference classes, as we will see in Chapter 2, has been variously linked with the social determination that certain bodies were superior or inferior, which has consequently impacted on our understanding of disability.

\section{Disability everywhere and nowhere}

Historian Lennard Davis has argued that the anthropometric measurements and systematic setting of the 'normal' body's limits that took place in the nineteenth century led to significant and enduring changes to our understanding of disability. As the rise of eugenics-based statistics worked to create a standard of 'normalcy', increased measurement and statistical analysis created a symbiotic relationship between what could be defined as the 'normal' body and the 'disabled' body. ${ }^{12}$ As this book will demonstrate, such strict dichotomies were challenged by individuals who disputed their status as normal or disabled, especially in compensation disputes. Davis focused especially on 
deafness to argue that 'the problem is the way that normalcy is constructed to create the "problem" of the disabled body.' ${ }^{13}$ Davis's work highlights what has become an important part of disability history. That is, acknowledgement of the fact that the construction of normalcy and deviance from normalcy (disability) is dependent on the time, place and context in which the judgement is made. Although this book takes a similar theoretical stance to Davis, it differs in its focus on the interwar years in Britain and in its critical emphasis on measurement technologies. While Davis drew attention to the power of statistics, I extend his argument to argue that technological instruments have been underestimated as crucial tools for developing our conceptualisation of disability.

For instance, the complex connection between deafness and sound technologies continued in interwar Britain, I argue, when the telephone became a tool for identifying and categorising hearing loss. The telephone's power in interwar Britain was linked to the fact that between 1912 and 1981, the British Post Office had control over a nationalised telephone system. Bell's Telephone Company was the first independent telephone company and Alexander Graham Bell (1847-1922) fought zealously to retain his right over the telephone patent, making himself a fortune in the process. ${ }^{14}$ However, eventually Thomas Edison's (1847-1931) competing telephony company forced Bell to co-create the Bell and Edison telephone company and the Edison Gower-Bell Telephone Company of Europe, which extended one long arm of its monopoly into Britain with the National Telephone Company (the NTC). Therefore the Bell and Edison conglomerate controlled most of telephony in Britain. That is until the 1880 ruling on the 1869 Telegraph Act mandated a nationalised service, which was summarily instated in 1911. The 1869 Telegraph Act had granted the UK government a complete monopoly over all communications and it was confirmed in 1880 that this Act included telephony even though the telephone had not been invented when the Act was first conceived. ${ }^{15}$

The telephone in interwar Britain was an important tool in both the identification and categorisation of individual hearing loss, and the ability to hear normally was both defined and moderated by the telephone. Linkage between telephony and hearing has long been noted by historians of sound and science, and Post Office engineers in the interwar period had considerable expertise in both telecommunications and hearing assistive devices. Telephone technology thus contributed to increased quantification of the human body and the interwar shift towards mechanised practical measures of hearing.

Using machines in this way led to what Daston and Galison term 'mechanical objectivity'. In their framing, technologies such as photography led to distrust in human visual perception due to expectation of perception; so it was 
feared that scientists were irrevocably biased by their expectations and that only machines could be trusted to be objective and honest. ${ }^{16}$ They point out that by the late nineteenth century, mechanical objectivity was installed as the guiding ideal of scientific representation across a range of disciplines, including medicine. ${ }^{17}$ For instance, in Chapter 4 we will see that the mechanised standards of hearing set up by the telephone system enabled the quantitative measurement of hearing through the audiometer. This circumvented the need to rely on the subjective assessment of personal hearing loss and allowed for the graphical inscription of individual deviation from 'normal hearing' - a term which I contest and problematise in Chapter 3 and Chapter 4. Indeed, the claim that audiometers provide a trustworthy representation is highly contentious: hearing is facilitated by the whole body and the way we access speech is dependent on a variety of factors, including accent, speech, facial expression and lip-reading. Communication is a two-way street, after all. Indeed, historical analysis of the long and difficult process of training machines to hear speech clarifies the fact that hearing is more complex than a simple mechanical process, 'spectrographic data had to be further quantified and expressed mathematically in order for a machine to "objectively" discern patterns that were apparent to the "subjective scale" of the ear or eye. ${ }^{18}$ As Chapter 4 outlines, claiming to be able to measure hearing was largely a matter of technocratic control which was often at odds with the experience of those subjected to such measures.

Patient reporting of symptoms was thus downgraded in a way memorably described by Jewson as resulting in 'the disappearance of the sick man. ${ }^{19}$ While Jewson's original analysis related primarily to the social changes that attended the shift from bedside medicine to hospital medicine, he also argued that the technical apparatus used in 'laboratory medicine' at the end of the nineteenth century further objectified the body of the patient. ${ }^{20}$ Daniel Goldberg has maintained that this naturalistic epistemic framework is best described as 'somaticism' - a focus on materially identified body pathologies endorsed by the ideology of mechanical objectivity. ${ }^{21}$

In this book, I extend these analyses to the interwar years in Britain, and argue that at that point, measurement instrumentation became a crucial component of the process of measuring disability and numbering normalcy. Tools like the audiometer and the spirometer defined disability as measurable pathology within the epistemic framework of mechanical objectivity, which linked instruments with impersonality, and thus with truth. ${ }^{22}$ The subsequent pursuit of standardisation reflected an attitudinal shift in the twentieth century that meant many no longer considered individual perception to be sufficiently accurate, or to be an appropriate channel for measurement. Since instrument 
users had to trust the maker, materials and theory embodied in the device, this meant trust was not automatically assumed; often, users artificially privileged preferred values by using easily measurable (surrogate) parameters to achieve practical ends. ${ }^{23}$ Trust was embedded in machinery and preferred to the kind of knowledge that could be generated by the individual human body.

The natural sciences' embrace of mechanical objectivity during the interwar years occurred alongside a crucial change in the tone of wider ideological thinking about society in Britain. While industrialising Victorian Britain was characterised by broad social and cultural confidence in empire and industry, the interwar years featured growing pessimism and fears of British decline and degeneration, alongside the apparent rise 'of the survival of the unfittest.' ${ }^{24}$ The 1904 Committee on Physical Deterioration was set up to explore how realistic these fears were and, while it found no evidence of overall decline, it did posit that poor food choices could be one of 'the causes to which degenerative tendencies might be assigned. ${ }^{25}$ Such statements, which presented degeneration as evident and apparent, added to the growing public rhetoric of deterioration. ${ }^{26}$ Its expression was funnelled, increasingly, through the conduit of eugenics - the pursuit of the exceptional man initiated by Francis Galton (1822-1911).

The eugenics paradigm rested on a social determination of idealised bodies positioned in opposition to the abnormal. I argue in Chapter 5 that the historical use of reference classes in spirometery was linked with and supportive of this framework. Spirometry was originally designed in the late nineteenth century to quantify the volume of air that an individual could exhale as 'vital capacity'. At this point, the spirometer presented vital capacity as lung capacity and its usage was often extrapolated into the measurement of normal breathing. Yet using this measure as representative of health or even levels of breathlessness was immediately problematic.

Normal breathing was never for all; rather, the spirometer was employed to enhance the differences between us. Spirometric data sets were specifically constructed around groups, which promoted the idea of normalcy within certain social groups (such as coal miners). This had drastic consequences in impeding the availability of occupational compensation for respiratory disability.

In Chapter 3 and Chapter 5 I show that technologies such as the spirometer and audiometer led to increased quantification of the human body and a shift towards more mechanistic perception which intensified the need to assign equivocal values to scale applicable measures of normal hearing and normal respiratory function. The impetus behind the reduction of these multidimensional sensorial qualities stemmed from powerful bureaucratic forces 
for which classification was especially important, namely, the British Post Office and the Medical Research Council (MRC), and I detail the importance of these two bodies to British society during the interwar years and explain the drive behind their standardisation of normalcy. In these chapters I make visible the invisible workings of these technologies, and in Chapter 4 and Chapter 6 I detail their consequences for individual bodies by exploring how standard thresholds of normalcy impacted on assistive technologies such as hearing aids and respiratory prostheses.

Scholars including Ian Hacking, Ted Porter and Stephen Jay Gould have all linked eugenic thinking to the expansion and veneration of measurable, numerical data. I situate their arguments within the historical context of the nineteenth century in the next section of this chapter. However, at this point, I simply point out that for all their insight, it is puzzling that such scholars did not recognise the relevance that their analysis had on the categorisation of disability. With the exception of the work of the aforementioned Lennard Davis, these classic texts linking the rise of standardised classification systems to eugenics do not make the leap to connect biometrics to disability.

Disability is everywhere and nowhere in these texts. And, as disability historian Douglas Baynton points out, disability is everywhere in history. As he puts it, 'there are no histories in which a disability analysis would be out of place and many that are diminished by its absence. ${ }^{, 27}$ Indeed, Baynton elucidates the fact that the concept of disability was integral to eugenic thought and practically expressed in the United States through anti-immigration laws that were designed broadly to safeguard against abnormal individuals entering society. ${ }^{28}$ Such concerns were allied to the twentieth-century culture of industrialisation and efficiency, 'a culture that was increasingly intolerant and afraid of difference.'. Twentieth-century standardisation of medical practices took place against a background of standardisation which extended into the home and the office.

The industrialist Frederick Winslow Taylor's attempts to standardize all aspects of the workplace, including the workers, the need to develop standard sizes for the ready-to-wear clothing industry, and the emerging field of life insurance and the apparent link between height, weight, and health all contributed to a growing tendency to see the human body in terms of statistical averages established through rigorous scientific investigation. ${ }^{30}$

The body of the patient, too, became conceptualised within this universal standardisation framework and the increased intolerance of difference resulted in an analogous standardisation of disability. As Baynton's immigration example demonstrates, disability is a particularly important grouping to 
study because it allows us to consider how it functions as a key defining social category alongside the categories of race, class and gender. ${ }^{31}$ It also reinforces historian Catherine Kudlick's compelling insight that when we are studying disability we are in fact studying power. ${ }^{32}$ Such power is often attached to numerical data.

Why was the Post Office involved in standardising normalcy thresholds? To understand its role in our story, we need to go back to the late nineteenth century, and the beginning of telephony. ${ }^{33}$

In 1874, Scottish-American inventor and teacher of the deaf Alexander Graham Bell managed to procure a dissected human ear 'fresh' from a recently deceased cadaver. He attached this to a needle and was thus able to transcribe sound waves onto smoked glass. ${ }^{34}$ This was one of the experiments that eventually led to the 'invention' of the telephone, which was patented by Bell in 1876. Bell's obsession with deafness, his desire to cure it, or to at least make speech visible so that lip-reading and forced speech could give the appearance of a cure, is well known. His mother was deaf, and his father and grandfather were both elocutionists. Bell's visible speech (a kind of physiological alphabet used for oral instruction) was the invention of his grandfather, Alexander Melville Bell. ${ }^{35}$ And, like his father and grandfather, Alexander initially worked as an elocutionist. He moved to Canada in 1870, and then to Boston in 1871 to take up work as a teacher of the deaf. ${ }^{36}$ It was there that he met Mabel, the student that he would eventually marry. The neurologist Oliver Sacks memorably described Bell's life-long obsession with curing deafness as 'half-terrible, half-promethean'-like in its fury and vigour. ${ }^{37}$ This fury had far-reaching effects. Multiple scholars have demonstrated the extent to which Bell's promotion of oralism helped to enact it as the only suitable method for teaching the deaf following the infamous 1880 Milan Conference which forbade sign language and forced generations of deaf children to undergo unsuitable and cruel education practices. ${ }^{38}$ Oralism was further motivated by Christian ideology which emphasised that citizens must be able to speak to claim the right to abode in the kingdom of heaven. ${ }^{39}$ One had to be able to speak to affirm one's faith, and (under Roman law) to claim property, which meant that oralism was heavily promoted by aristocratic families where interbreeding had caused hereditary deafness that subsequently threatened their ability to retain their lands and property. ${ }^{40}$ As Douglas Baynton notes, simply 'to be human was to speak. ${ }^{41}$ The practice of oralism used various breathing techniques to make the voice visible and then audible. The spirometer was thus used in the nineteenth century in deaf education as well as in medical researches into respiration. ${ }^{42}$ Deafness echoes through technologies as varied as shorthand, multiple telegraphy, oralism, speech therapy and, above all, telephony. ${ }^{43}$ 
The Post Office brought telephony under its control through its unique position as an office of state that also had to function as a profitable business. Stephen Tallents, the public relations guru who spearheaded the Post Office's major rebranding campaign during the 1930s, articulated the conflict of interest between profit and the state that was integral to the Post Office in the interwar years:

The Post Office of today is a combination between great business corporation and a government department. As such its publicity ... must be organised to combine, with such modifications as its special position demands, the welltried methods of commercial advertising and the wholly unexplored and almost wholly unpractised methods of government publicity. That combination breeds certain advantages and certain difficulties. ${ }^{44}$

As a result of what Tallents termed its 'special position' within the government, the Post Office developed amplified telephone technology according to its changing relationship with the Treasury, whose priorities regarding welfare were simultaneously in flux. The certain advantages alluded to by Tallents included the total control that the Post Office had over the telephone network. But this state backing also meant that it was required to work under the demands and financial constraints of the Treasury and act as an arm of the wider government. For this reason, the state and the newly enfranchised public expected the Post Office to provide telephones that could be used by people with some hearing loss. Amplified telephony was thus developed alongside the embryonic welfare state.

Writing history based around the activities of the Post Office is challenging because of its institutional set-up. The interwar structure of the Post Office business model complicates and conceals the agency directing amplified telephone development. Until the Bridgeman Report was instigated by the wider government in 1932, the Post Office Telecommunications Department was run on the same lines as its predecessor, the National Telephone Company. However, the rapid growth of its telephone network put pressure on the larger Post Office operation. This pressure was exaggerated by the fact that any problems related to engineering had to be referred to the Engineer-in-Chief in London and this meant that any changes to equipment became extremely complicated. This also led to internal disputes, as historian CampbellSmith has explained: 'Local telephone operations were run from day to day by twenty-eight "District Managers", ... who were not entirely comfortable being subordinated to colleagues with no technical training whatever. ${ }^{25}$ In practice, this meant that all complaints about the efficacy of the amplified telephones and planned changes to their design were filtered through the London 
Office at St Martin's Le Grand via the Engineer-in-Chief's research station at Dollis Hill. It is thus sometimes difficult to recover agency in the direction of telephone improvements, as individual actions were immersed in extensive bureaucracy. The Telecommunications Department of the Post Office exemplifies an office hidden behind its role as a cog driving the larger Post Office 'Government Machine', with its role in providing a telephone for people with hearing loss 'marked by opaqueness and discretion. ${ }^{46}$

Like the British Post Office, the MRC was part of the government but remained apart from it. As discussed earlier in this chapter, the interwar years were permeated by pessimistic ideas about degeneration and featured a succession of governmental social surveys, largely targeted at children and the working classes. Researchers worrying about 'physical efficiency' designed studies on nutrition and minimal calorie intake, which prominently featured attempts to objectively calculate individual physical needs. ${ }^{47}$ Interrelated with such health concerns were economic worries, especially since the 1911 National Insurance Act had begun providing disability benefits and free medical treatment for insured workers. ${ }^{48}$ The Act gave special provision for the treatment of tuberculosis for both the insured and their dependants, partly to ensure that Britain kept up with Germany, who were the major threat invoked in relation to 'national efficiency'. 49

Crucially, research into tuberculosis was also included in the 1911 proviso, and by exploiting this research clause the Departmental Committee on Tuberculosis was able to morph into the broader Medical Research Committee. The outbreak of war in 1914 severely curtailed the planned tuberculosis research. However, the department's contributions to medical science throughout the war were afterwards deemed essential by the War Office. These contributions were especially directed towards the compilation, sorting and classification of medical statistics. The MRC combined the medical and surgical statistics of military hospitals in an enterprise of 'formidable' import. ${ }^{50}$

Therefore, in 1919 the Medical Research Committee was re-designated as the Medical Research Council. ${ }^{51}$ The fact that it was directly responsible only to the Privy Council meant that the MRC was endowed with significant freedom in its organisation and investigations into a variety of medical and biological researches. This research diversity meant that during the interwar years, the council was split into numerous sub-sections which were usually represented by committees, research boards or advisory boards with specific focal points. ${ }^{52}$ Wider interwar concerns about 'National Efficiency' were allied with the MRC's drive for standardisation, especially of anthropometric measurements. The war had highlighted the need for fixed, standardised measurements in the medical sciences, and the MRC believed that Britain was falling behind 
other countries, becoming subject to other standards rather than setting them. In Austoker and Bryder's terms: 'Standardization thus assumed not just scientific or medical but also economic and political significance. ${ }^{53}$

In Chapter 5 I make the argument that the MRC's focus on medical statistics impeded recognition of the risk of coal-dust to miners' lungs. Yet ironically, the MRC's focus on medical statistics in the twentieth century overwhelmingly aligned with its increased recognition of the social determinants of health. For instance, after the Second World War the industrial health research board of the MRC sponsored a wide-scale survey on the occupation factors implicated in ulcers. ${ }^{54}$ Many of the clinicians working for the MRC in the interwar years and after were politically left-wing, and emphasised the impact that social deprivation, malnutrition and living conditions had on health. ${ }^{55}$ MRC researchers like Richard Doll (1912-2005) and Archie Cochrane (1909-1988) were not only cognisant of the environmental causes of illness, they instituted practices in medical statistics and epidemiology (such as the randomised control trial) to reveal them and force the instigation of public health measures. Concurrently, the randomised control trial helped to usher in an era of measured quantification directed towards the simultaneous standardisation of medical practice and the patient. ${ }^{56}$

\section{Measurement matters}

The idea that numerical measurable data has privileged (and powerful) epistemological significance is sometimes referred to as the 'Curse of Kelvin', because of a remark he made to the Institute of Civil Engineers in 1883: 'I often say that when you can measure what you are speaking about, and express it in numbers, you know something about it; but when you cannot measure it, when you cannot express it in numbers, your knowledge is of a meagre and unsatisfactory kind. ${ }^{57}$ Kelvin's implicit suggestion was taken to mean that ease of measurement should therefore be prioritised over theoretical accuracy. That is, what cannot be easily measured can be at best dismissed, and at worst denied. The problem with this has been most thoughtfully articulated by Graeme Gooday in his classic study of the measurement of electricity, in which he writes:

If privileged significance is attached only to that which is easily measurable. Then those people who cherish what cannot easily be thus quantified are likely to experience injustice or at least marginalization. Less extreme, but of great significance to this volume, is that such unfortunates may find their positions all too easily devalued by quantitative experts as deficient in (numerical) evidential support or even as grounded on mere speculation or delusion..$^{58}$ 
Gooday follows this preface remark with a thorough study of the intersections between measurement, trust and instrumentation in the context of nineteenth-century electrical technologies. Part of his argument rests on the claim that because the human body was no longer trusted as a reliable vector of knowledge, individual testimony was subsumed through the use of reliable laboratory instruments. ${ }^{59}$ Measuring Difference, Numbering Normal extends this argument to the arena of healthcare in the twentieth century to explore how personal testimony about the body has been commodified, then devalued by standardised measurement technologies and indirect measurements.

There are two kinds of measurement: direct and indirect. Direct measurements are primary values that are measured directly through a system or tool. Examples include measurements of weight, height, size, temperature, time, capacity and so forth. However, indirect measurements make inferences from another parameter, usually when direct measures are unavailable or unobservable. Gooday has termed such indirect measures 'proxy' or 'surrogate' measures. As the section below will discuss in detail, head size, IQ and life insurance are all examples of proxy measurements.

An above-mentioned example of such artificial privileging of measurement in healthcare is the Body Mass Index scale, which was originally invented by Adolphe Quetelet (1796-1874). Quetelet was a mathematician and astronomer who introduced statistical methods to the social sciences. ${ }^{60} \mathrm{He}$ did pioneering work in what we would now term cross-sectional-style studies of human growth, and developed 'the Quetelet index', a formula that estimated whether a person was healthy by dividing their weight by height in metres squared. This method of measuring health was dubbed the 'Body Mass Index' by Ancel Keys in 1972. But its ancestor the Quetelet Index was developed and used by actuaries and insurers as a strong predictor of health and mortality throughout the nineteenth century. ${ }^{61}$ Using this scale, they could make inferences about health based on direct measurements of height and weight. However, in terms of gaining significant information about health, measuring body fat against body mass would be better, but measuring that has been historically far more difficult, time-consuming and expensive. Instead, BMI was used. Ease of measurement should not be underestimated as a powerful reason for choosing one kind of measurement over another. The BMI scale demonstrates how the artificial privileging of measurement is perpetuated. Indeed, for most of his career, Ancel Keys (though he coined the term) railed against its use as a measure of health, although he eventually gave up attempts to institute the more precise but far more difficult measurement of adiposometry (using callipers to measure skinfold fat). ${ }^{62}$ I make this point not to decry 
the usefulness of BMI to clinical studies, but simply to reinforce the point that it is artificially privileged as a simple and cheap indirect measurement.

Easy quantifiable measurements are thus elevated as objective, and yet indirect or proxy measurements are necessarily subjective. For instance, other examples of proxy measures in healthcare include fMRI (functional magnetic resonance imaging or functional MRI), which does not directly measure neuronal activity, but rather measures 'the indirect consequences of neuronal activity ${ }^{63}$ Changes in neural activity are associated with oxygenated blood, and oxygenated blood has different magnetic susceptibility, so fMRI measures blood oxygen levels as a proxy for neuronal activity. Similarly, in economics, the unemployment rate is used as a proxy for the health of the economy; a notable example of a measure that can be manipulated, for instance by counting zero hours contracts in labour market statistics related to employment. Similarly, GDP (gross domestic product) is used as a proxy for quality of life. Yet GDP is far more subjective than it seems. Measuring GDP is a blended measurement, characterised by judgements about what should be included in its definition. Scholar Marilyn Waring has therefore argued that GDP can distort our economic reality through its perpetuation of patriarchal values. ${ }^{64}$ Breastfeeding, for example, is not currently included in Britain's GDP despite the contributions to the economy that it makes based on its health benefits for infants, which results in cost benefits like fewer hospital visits. ${ }^{65}$ Its exclusion has had the unfortunate consequence of elevating the contribution of formula milk to the economy, while simultaneously lowering the contributions of breastfeeding mothers and hence contributing to the gender pay gap. ${ }^{66}$ GDP is 'not like measuring how high the mountain is. ${ }^{67}$ Proxy measures are therefore more likely to be easily manipulated, more likely to miss key information and more likely to denigrate important information. Their enduring appeal, however, lies in their greater propensity to quantification and scalability.

The problem with numbers on a scale, though, is the potential of distance between them. One apposite example is the decibel scale we use to measure sound, which is logarithmic rather than linear. That is, each value is multiplied by an order of magnitude. Whereas on a linear scale, the variation between one and two is the same as that between seven and eight, on a logarithmic scale, variation between values increases in proportions. This can be problematic when numbers are elevated as markers of objectivity and inappropriately used to represent qualitative research concerned with non-additive units. Jane Macnaughton has identified that 'the important point is that when qualities are arranged in a series and identified with numbers, the use of those numbers 
to do calculations such as averages or percentages is meaningless, since the relation between points 1 and 2 and between 5 and 6 in the series may be completely different. ${ }^{68}$ Eula Biss has written beautifully of how this lack of meaning manifests in the numerical scales used to measure pain, asking: 'where does pain worth measuring begin? With poison ivy? With a hang nail? With a stubbed toe? A sore throat? A needle prick? A razor cut? ${ }^{69}$ As Joanna Bourke has outlined, the historical imperatives driving the creation of such scales were linked to the drive to bring objectivity to the idiosyncratic experience of pain. ${ }^{70}$ Yet many have pointed out that any pain scale rests upon a fixed zero point of no pain, or an average ideal of normalcy. Even scales that dispense with numbers altogether, such as the Wong-Baker scale, are subject to this criticism. As the writer Abby Norman memorably put it in her critique of this scale: 'It has cartoon faces wearing expressions that range from Kurt Vonnegut's "Everything is beautiful and nothing hurts" to Leslie Knope's "Everything hurts and I'm dying"'?1 Individual normalcy is inevitably personal, and interrelated with an individual's experiences, culture, environment and history. Indeed, the idea that normalcy as an average of many can tell us anything meaningful on the individual level may be entirely misguided.

In Georges Canguilhem's classic exploration of nineteenth-century medicine, he critiques the idea that pathology is the same as normal function and only differs quantitatively. ${ }^{72}$ Canguilhem makes a crucial distinction between individual normalcy and the normal as an average. That is, what is considered normal as an average of many might not account for the variance of individual functioning. Moreover, Canguilhem questioned the conflation of divergence with abnormality, arguing that 'in order to represent a species we have chosen norms which are in fact constants determined by averages. The normal living being is the one who conforms to these norms. But must we consider every divergence abnormal ? ${ }^{73}$ An example used in Cryle and Stephens's genealogy of normalcy vividly illustrates just how the average can work in opposition to individual variance, which I now discuss. ${ }^{74}$

In 1945, two statues were displayed in the American Museum of Natural History in New York. ${ }^{75}$ Named Norma and Normman, they were carved from alabaster and were made by a gynaecologist called Robert Dickinson working with the sculptor Abram Belskie to represent the 'perfectly average' American body. A competition was held to 'find Norma' but, although there were thousands of applicants, no one American woman embodied these average measurements. Not even close: as Todd Rose explains, fewer than ' 40 of the 3,864 contestants were average-size on just five of the nine dimensions' and none of them were close to the average of all the measurement dimensions. ${ }^{76}$ The unfortunate American contestants who failed to meet the ideal represented by 
Norma were chided for being 'unhealthy and out of shape. ${ }^{37}$ Conversely, when the same finding was made in 1952 in relation to Air Force pilots who did not fit cockpits designed for the 'average man', the discovery led to the development of ergonomic design in cockpits. ${ }^{78}$ However, as Rachel Weber has explained, using ergonomic designs based on the anthropometric measurements of men still led to the exclusion of women and shorter-statured men. Even when the ninety-fifth and fifth percentile male dimensions were used as guidelines, 'the gap between a 5th percentile woman and a 95th percentile man can be very large. ${ }^{79}$ And there is more to this story. The fact that Dickinson's statues were carved from alabaster is not the only reason that they looked white. This is in fact because of the data sets that were used to create the averages for the statues. Normman's data came from records of First World War soldiers that had been collected by the eugenics records office, whilst Norma's came from the anthropometric measurements of 15,000 'native white' American women which had been gathered by the Bureau of Home Economics to create a standardised system of sizing for readymade clothes. ${ }^{80}$

Thus, the subjects that we decide to measure as standard have an important influence on our conception of normalcy. Such standardisation can have particularly pernicious effects in healthcare if we equate normalcy with whiteness or maleness. For example, historian Heather Prescott has argued that US college physicians used students to establish paradigm 'standards of normality' across a range of bodily functions, including 'blood pressure, lung capacity, pulse rate, basal metabolism and other physiological processes. ${ }^{81}$ In establishing these standards, any students with any sort of disability was excluded, as were women, as 'researchers also continued to assume that students, particularly white males from the upper middle classes, best represented the normal human population. ${ }^{82}$ This decision, Prescott argued, was politically motivated. Not only were white male students considered ideal specimens to represent humanity, they were also assumed to be the best group to study because they were the 'most valuable to society. ${ }^{83}$

A similar case of politically motivated measurement occurred in 1994, when a group associated with the WHO met to define normal bone density. In this meeting, young women were chosen to represent the standard of normal bone density. Peter Gotzsche argues that

the group - completely arbitrarily - defined osteoporosis as present if the bone mineral density was 2.5 standard deviations below that in a young woman, and didn't even stop there, but defined osteopenia as present if the measurement lay between 1.0 and 2.5 standard deviations below. These criteria were intended for epidemiological research but were a bonanza for the drug industry, as they rendered half of all older women 'abnormal'. ${ }^{84}$ 
Gotzsche suggests that the fact that a drug industry sponsored the meeting was not unrelated to the creation of this standard. And these examples lead us to more substantial questions about how we measure health. How arbitrary are the thresholds we use in healthcare? How much are they influenced by the form and ease of measurement? How has the drive for quantified data shaped our conception of the normal as strictly dichotomous to the abnormal?

Strict dichotomies have also characterised the literature concerning disability and measurement. Disability studies developed as a discipline relatively recently, concurrent with social changes concerning the perception of disability and the work of activists campaigning for greater rights for the disabled, starting around the mid-1980s. ${ }^{85}$ It is important to emphasise this grounding in political activism because this has influenced the kinds of histories that have been told about disability, and has oriented the focus of these histories. For example, campaigns for greater rights for the disabled in the US have been linked by historian David Gerber to the impact of the Vietnam War. ${ }^{86}$ Thus, veterans were the first major group to instigate the fight for greater recognition of disability rights. Reflecting the strongest aspect of disability activism and political interest, research into disabled veterans has been a major component of disability history.

Understanding the quantification of sensorial symptoms poses a challenge of epistemological as well as historical significance and thus necessitates engagement with philosophical theory as well as relevant medical and disability history. While disability history has received increased scholarly attention in recent years, it has not often engaged with science and technology studies, partly because of politicised concerns about medical technologies functioning as tools of oppression.

As the title suggests, Measuring Difference, Numbering Normal instead provides a detailed study of the technological construction of disability by examining how the audiometer and spirometer were used to create numerical proxies for invisible and inarticulable experiences. This is particularly relevant to our understanding of unseen but experiential disability. The audiometer was critical both for providing proof of hearing loss in the industrial/ military complex, and for managing the threat posed by 'hysterical' deafness and malingerers. When instrumentation was used in this way and conflicted with an individual's own perception of health, I argue that this created a specific kind of instrument-based epistemic injustice - mechanical epistemic injustice. In Chapter 2 I discuss how these instruments have been used in relation to disability measurement to perpetuate mechanical epistemic injustice. I argue that as well as the distinctive kind of epistemic injustice levelled at the disabled there is further such injustice inherent to the processes of 
instrument-based confirmation testing that compensation or social support often necessitates.

However, while this book does explore the experience of hearing loss, it does not focus on Deaf history, which has been thoroughly explored by others. ${ }^{87}$ Rather, it is concerned with the experiences of the 'deafened'. That is, those who identify as hearing and experience their hearing loss as a loss. ${ }^{88}$ Indeed, this book is unique in its specific consideration of late-onset disability, which means the subjects under consideration are unlikely to have identified as disabled. Both hearing loss and breathlessness are associated with ageing and entail negative stereotypes that can be avoided by hiding or rejecting the related assistive technology. ${ }^{89}$

Both hearing and breathing are invisible, and so, too, are hearing loss and breathlessness. This categorisation conflict is highly relevant to the themes of this book. The medical measurements designed to quantify and define hearing loss and breathlessness are often incongruent with extremely diverse and individual conditions and experiences. Indeed, this project is of significance precisely because of the amorphous nature of the phenomena under consideration; that is, the fact that breathing and hearing are singularly difficult to measure and standardise. There are other pertinent commonalities between hearing and breathing. Air is the medium through which we hear. As both noise and air pollution move through space, they resist easy quantification and measurement, making them difficult to regulate. Similarly, hearing and breathing are characterised by extreme diversity in personal experience, which similarly eludes fixed representation. Hearing and breathing are experienced and facilitated by the whole body and our understanding of how these processes work is still somewhat uncertain. ${ }^{90}$ As Williams and Carel explain, 'breathlessness is a unique medical symptom and experience that of its essence involves sensation, cognition, and reasoning, none of which are reducible to the other.91 To understand multisensorial phenomena, I argue that we need a multidisciplinary approach, blending science and technology studies (STS) approaches with medical history and disability history.

Disability studies is often multidisciplinary; and invites scholars to think about disability not as an isolated, individual medical pathology but instead as a key defining social category on a par with race, class and gender. Disability studies is not concerned with analysing human variation, rather it considers how we define categories of variation and make them meaningful. ${ }^{92}$ In focusing on these definitional processes, disability studies made use of the influential concept of the social model of disability. The history and development of this concept will be explored in full detail in the following chapter but to put it most simply, the medical model defines disability as located in an individual's 
pathology, whereas the social model defines disability as resulting from environmental barriers which impact on the individual's ability to live and work. The stark division between the social and medical model of disability has meant that collaboration between science and technology studies and disability studies has been regarded as counterproductive and even inappropriate. The social model presents particular problems for historians because it does not fit with the idea that 'the impaired body is part of the domain of history, culture and meaning, and not - as medicine would have it - an ahistorical, presocial, purely natural object. ${ }^{93}$ Technology and medicalisation have been negatively linked in the minds of many, and likewise associated with the oppression and normalisation of disability by the medical profession. Therefore, certain proponents of disability history define the discipline explicitly in opposition to medical history. ${ }^{94}$

In this research, by contrast, answering what motivations underpinned the development of the spirometer and audiometer necessitates studying technology alongside disability history. Historian Julie Anderson has argued that it is essential to consider medical as well as social developments in disability history to reveal the full lived experience of individuals. ${ }^{95}$ Too narrow a focus on the social model of disability risks missing the perspectives and experiences of the users of technology and their reciprocal impact on measurement technologies.

Furthermore, while the social model has been incredibly successful in forcing through legislative changes and in creating a radical and effective politics of disability, its theoretical framing has led to conceptual criticism. ${ }^{96}$ For example, the social model's separation of body from impairment risks disowning medical approaches to the extent that it implies that impairment is not a problem. ${ }^{97}$ The social model therefore risks eliding the importance of the body and its impact on our health. We are becoming increasingly aware that the Cartesian separation of mind and body has prevented us from realising the importance of biography to health..$^{98}$ The blurriness of the distinction between mind and body has been repeatedly shown in studies concerned with breathlessness. For instance, neuroimaging studies demonstrate that an individual's past experiences and personal psychology mediate their experience of breathlessness. ${ }^{99}$ Both the mind and body process breathlessness, and, relatedly, its severity does not correlate with disease stage. ${ }^{100}$ However, prior experiences, expectations and individual psychology do impact on the effect of breathlessness, much like the feeling of pain. ${ }^{101}$ Parallels with pain are also notable in studies that show that vicarious dyspnoea (breathlessness) can be induced in empathetic individuals watching others struggling to breathe. ${ }^{102}$

Breathlessness thus offers distinct challenges for those attempting to measure it. The 'Life of Breath' project has been designed to explore this as part of 
its remit to investigate how the humanities can shed light on the experience of breathing and breathlessness. ${ }^{103}$ As such, many of its publications have illuminated the personal and intangible nature of breathing and breathlessness. Moreover, project research has demonstrated that objective measurements have been assumed to correlate with the lived experience of breathlessness, so that 'breathlessness has for the most part been subsumed by objective measurements. ${ }^{104}$ This research represents the increasing awareness of disconnect between the subjective individuality of breathlessness and attempts to mark out a numerical correlation. In fact, the premise of being able to achieve a reliable and valid objective measurement of breathlessness has recently been called into question by physiotherapist David Nicholls, who argues that:

The importance placed upon achieving a reliable and valid objective measurement of breathlessness is confusing a basic fact. Breathlessness is a unique human phenomenon that can be understood and interpreted only by sufferers. In that sense no amount of objective complexity will ever obtain a true representation of a sufferer's experience. ${ }^{105}$

Thus, two crucial tensions are presented by the usage of standardised frameworks in medicine applied to the more intangible aspects of ourselves (like breathing and hearing) through instrumentation. Firstly, in the correlation between subjective experience and objective measurement; and secondly, in the question of what exactly is being measured through tools like the spirometer.

Now, perhaps more than ever, data sits higher in the hierarchy of medical knowledge than the kinds of knowledge gained from subjectively experienced symptoms and embodied experience. Do my experiences matter as much as the data that I generate? A position that prioritises such data (implicitly or explicitly) suggests that quantifiable numbers are understood as neutral, objective and valid in a way that lived experience is not. Moreover, normalcy and the normative standards embodied in instrumentation have often rendered themselves invisible to both the measurers and the measured.

\section{A normal history}

Even our idea of the word 'normal' as the opposite of abnormal or pathological has a long and obscure history. The term originated from geometry as a way of describing the relationship between lines. ${ }^{106}$ In what we might term the 'prenormal' era, alternative words such as orderly, regularly, natural and virtuous were used, but historian Caroline Warman contends that such conceptions of normality were tied: ' (a) with measurement and senses of straight or deviating lines (b) moral and sexual behaviour, and thus, with binaries of values which 
are generalised into morality'. ${ }^{107}$ These links between measurement, morality and normalcy were strengthened by the work of Adolphe Quetelet.

As well as developing height and weight tables to study the relationship between them, Quetelet demonstrated that normal distribution could be applied to physical attributes of humans through population studies. ${ }^{108}$ So, he applied normal distribution to human qualities. Starting with height, Quetelet showed that when individual characteristics were measured the values tended to cluster around the average, 'the polygon of frequency tends towards a so called "bell-shaped” curve' - in other words, the normal curve. ${ }^{109} \mathrm{He}$ thus developed the concept of 'the average man', and from this point the average was held up as the ideal - a shift that had significant consequences for our understanding of normalcy. As Neff and Nafus emphasise: 'This conflation of mathematically normal distribution with "normal" as a kind of ideal gives tremendous power to those who decide what to measure.' ${ }^{110}$ And, I argue, to those who decide who to measure.

Quetelet's ideas were taken forward by Francis Galton, but for Galton, the average man was not ideal, he was mediocre. ${ }^{111}$ Using quantitative statistical methods to investigate biological phenomena is closely linked to Francis Galton's researches. Charles Darwin's cousin, Galton believed that anything could be measured, and that measurement was the most important aspect of scientific study. ${ }^{112}$ This was reflective of his interest in measuring the exceptional rather than the average in order to facilitate the improvement of races. ${ }^{113}$ In 1883 he coined the term eugenics and advocated positive eugenics, that is, the promotion of 'good stock', through regulation of marriage and family size. Because of his interest in heredity, Galton's life work was devoted to accurate precision measurements of human characteristics and functions, based on instrument derived quantitative data. Certain aspects of his work betray his more idiosyncratic and subjective measures. For instance, his beauty map of the United Kingdom involved him ranking the women he met numerically and then putting them on a scale which put women from London on the top and women from the north-east coast of Scotland at the bottom. ${ }^{114}$

Eugenicists like Galton used the power and prestige attached to large amounts of data on head sizes to legitimate their claims about differences between races. As Stephen Jay Gould identified in The Mismeasure of Man:

The second half of the nineteenth century was not only the era of evolution in anthropology. Another trend, equally irresistible, swept through the human sciences - the allure of numbers, the faith that rigorous measurement could guarantee irrefutable precision, and might mark the transition between subjective speculation and a true science as worthy as Newtonian physics. ${ }^{115}$ 
Gould traces the history of intelligence testing from its inception in France as a way of identifying children that needed more help to its eventual mutation into a trusted measure of absolute intelligence. In doing so, he shows that IQ's design was predicated on the expected knowledge norms of its designers, meaning that users who were not immersed in an Anglo-American worldview were at an immediate disadvantage. Failure to recognise this led to the apparently damming objective claims concerning difference between races, which inevitably positioned white men at the top. Nineteenth-century scientists' elevated positions were thus reflected in the apparently objective hierarchy of nature. Thus, statistics about the human body gained authority in an increasingly eugenic framework which worked to quantify and rationalise the human body. Fear of disability was disguised in 'objective' biometrics such as those proposed by Galton's protégé, Karl Pearson (1857-1936), who set up a large-scale investigation into the racial qualities of Jewish schoolchildren and concluded that 'taken on the average, and regarding both sexes, this alien Jewish population is somewhat inferior physically and mentally to the native population." ${ }^{\text {'16 }}$

Gould argues that it is this kind of 'science' that Charles Murray and Richard J. Herrnstein restored in The Bell Curve in 1994, when they argued for the existence of inherited racial differences in IQ. ${ }^{117}$ Their analysis has been notably countered by the existence of 'the Flynn effect', which shows that there were IQ gains through time across all groups during the twentieth century, thus suggesting that it is environmental factors and perhaps specific features of modern living (such as increased leisure time, greater education and exposure to abstract concepts) that impact IQ difference. ${ }^{118}$ Yet even before the existence of IQ craniometrists believed that the shape and size of the head gave clues to reveal an individual's intelligence level by proxy. Head measurers focused on physical measurements of the skull; either on the outside, using ruler and callipers to measure various indices and ratios, or filling the cranium with seed or shot to measure the volume of the brain indirectly. ${ }^{119}$ Measuring skulls was popularised earlier in the nineteenth century by US scientist Samuel George Morton. Morton believed that the races could be ranked, and that the existing societal hierarchy was an objective reflection of nature. He could support this by citing the evidence of his rigorous measurements on large amounts of data. In fact, he was famously described as 'the objectivist of his age. ${ }^{120}$

Gould went to great lengths to refute the science behind the Bell Curve thesis, by actively recalculating and re-analysing the statistics used by craniometrist Samuel Morton to decisively demonstrate the subjective and biased nature of Morton's calculations. He thus demonstrated that Morton's data were unreliable and distorted by his preconceived views on the intelligence of the different races. Regardless of their precision, it is notable that these 
researchers chose arbitrary racial groupings over other possible categories and it is pertinent to question whether this led to increased acceptance of these classifications.

The statistical tools interrelated with these classification systems have been explored by philosopher Ian Hacking, who has argued that the 'avalanche of numbers' following this process was precipitated at a specific point in the nineteenth century, that is, $1820-40 .{ }^{121}$ Historian Ted Porter is less specific, but agrees that it was the nineteenth century that featured the initial drive for standardised quantitative measurement units. Porter has analysed how power to monitor, observe and normalise individuals was especially invested in single numbers as representative of truth and objectivity ${ }^{122}$ The association between single numbers and objectivity was strengthened in the 'measured world' of the twentieth century, and Porter has demonstrated that by the 1920s, there was a strong association between statistical methods and standardised IQ tests. Porter points out that IQ tests were privileged as a form of measurement in schools not just because of their perceived objectivity, but also because of their convenience and cheapness. And furthermore, as historian Dan Bouk reminds us, these objective measures impacted on individual subjectivities, through 'the power of statistical studies to inform ordinary people's understandings of themselves.' ${ }^{123}$

Such single numbers were used to demonstrate objectivity in the natural sciences, but soon extended into the realm of life insurance, which began in Britain in the mid-eighteenth century and became a signature feature of modernity around the world in the nineteenth century.' ${ }^{\prime 24}$ For example, in economic principles, the value of a life should mean just how much it is worth to the person living it. ${ }^{125}$ In practice, it was (and remains) difficult for people to put a quantitative value on their own existence. As a result, the measure used instead is the average lost income on death. Actuaries tried to arrive at a legitimate sum of money that could compensate families for the loss of the main breadwinner rather than attempting to determine a numerical monetary value for the incalculable value of life. ${ }^{126}$ This pragmatic move towards costbenefit logic has had significant consequences to public health, for example in the way that heart disease as the leading cause of death in men in the US was treated as a public health emergency while the fact that heart disease was the leading cause of death in women was ignored. This was because although heart disease killed both sexes at equal rates, it killed men earlier, while they were still working.

The assumption, then, that the leading cause of women's death was less of a public health emergency than the leading cause of men's death just because 
men were more likely to be affected at a younger age was, ultimately, a value judgement, though one consistent with the cost-benefit logic often used in the health-care arena, which emphasises the years of 'productive' life lost to illness. (It also raised the interesting question of how much of the underrepresentation of women in heart disease research was actually a consequence of the tendency to underrepresent the elderly.) $)^{127}$

As this book shows, the development of schemes designed to recompense for disability were similarly criticised for their apparently arbitrary scaling of disability levels. In this book, I link the analysis of historians and sociologists from STS focused on measurement and categorisation together with work from disability studies in order to make a radical addition to work on the social construction of disability. In arguing that technological processes have been ignored as important contributors to the classification of disability, I make these processes visible and reveal that seemingly purely technical issues such as how to categorise data thus has an important impact on what we consider to be natural. Kohrman explains that: 'At the close of the last millennium some of the most powerful institutional artefacts of modernity - nation states - came to define, standardize, and medicalize aspects of human existence under and within a relatively new social category; that is, disability. ${ }^{128}$ Large bureaucracies like the MRC and the Post Office exemplify offices of such administrative biopower.

Michel Foucault introduced this influential concept in The History of Sexuality in which he argued that, from the seventeenth century, 'there was an explosion of numerous and diverse techniques for achieving the subjugation of bodies and the control of populations, marking the beginning of an era of "biopower"'.129 Biopower is power over life, constituted of two separate forms. ${ }^{130}$ The first is concerned with the body as a machine, and the second pole is concerned with the body of species. It is the second form that is explored in this book through the context of early twentieth-century biomedicine. Hacking takes Foucault's concept further, to show that even the process of dividing people into categories for statistical analysis means that we need to then name these subdivisions and classify people into certain categories. This can, in turn, lead to the perpetuation of these artificial groupings as if they were real, natural entities. He explains that 'Counting is hungry for categories. Many of the categories we now use to describe people are by-products of the needs of enumeration.' $^{131}$

These newly created body categories exerted powerful influence over their subjects through the prism of medico-legal forces. Historian Lundy Braun's 2014 book, Breathing Race into the Machine, vividly illustrated the real-world consequences of these classificatory forces. Braun has shown that the practice 
of correcting for race in spirometry measurement promoted scientific acceptance of difference between racial groups, without due concern to the racial categories employed to organise this data in the first place, or to the way that social conditions and living conditions affected lung function in these groups. ${ }^{132}$ Further examples of biopower in action feature in historian Vanessa Heggie's work on testing sex and gender in sports, which shows that the tests we use to measure sex rely on arbitrary cut-off points which are strongly influenced by our cultural attitudes towards gender. ${ }^{133}$ Sex is, of course, very intimate, hidden and embodied and so attempts to standardise its measurement have been fraught and conflicted: 'The story of sex testing, and histories of sex testing, in international sport tell us a great deal about social attitudes to gender, and how the co-option of science in sport (however it is resisted by scientists and human rights campaigners) can act to essentialise social categories.' ${ }^{\text {'134 }}$ These essentialised social categories are all too often those associated with non-standard bodies. This is a reference class problem, and the threat represented by contested reference classes to the apparent objectivity of normalcy will be explained and further explored in Chapter 2.

In this context, measurement devices offered scientific objectivity but also offered a way to make the invisible visible. By this I mean not just invisible disability, but also the intangible characteristic of 'fitness' that concerned eugenicists. Indeed, while British eugenicists are often considered to have been more concerned with class degradation than with racial purity, Dan Stone argues that class and race were intertwined and inseparable in eugenic thought during the interwar period. Although class was central to British eugenics, the idea that 'there were two strands of eugenic thought, a German one emphasising race and a British one stressing class, was promoted, after the Second World War, by the eugenicists themselves. ${ }^{135}$ Moreover the fears of degeneration from 'alien' immigrants were consistently couched in terms that emphasised disability. Just as Baynton has outlined in the US context, so too in the interwar years in the UK the threat of immigration was highlighted in rhetoric connoting disability. Immigrants were described as 'inferior,' 'weak', 'feeble-minded', 'unfit' and as a national 'impediment.' ${ }^{\text {' }}{ }^{16}$

Measurement devices like the spirometer and audiometer were used during the interwar period not just to measure specific health features but rather to divine more generally some intrinsic quality of the measured. These devices were perfected in an era that was overwhelmingly concerned with degeneration and disability and ways of measuring these deviant attributes. In this way, these tools endowed such studies with a veneer of scientific objectivity and contributed to essentialist notions about certain group categories. 


\section{Resisting categorisation}

This book is framed around a comparative study of hearing loss and breathlessness undertaken through examination of the tools that were developed to quantify these experiences in Britain during the interwar period. Structured chronologically and divided into two main sections, the first on hearing and the second on breathing, these parallel case studies allow us to compare first the process of quantifying normal hearing and breathing, and then the impact this measurement had on a range of disability experiences; from wealthy businessmen disputing their levels of deafness and arguing that their phones weren't loud enough, to miners arguing that they deserved compensation for respiratory disability.

Such injustices are especially problematic for the kinds of disability where the experience of it constitutes its essence, and so in Chapter 2, 'Measuring disability', I elucidate the epistemological implications of the historical case studies which follow in Chapters 4 to 6 . These begin with hearing and start in Chapter 3, 'The artificial ear and the disability data gap', with an investigation of how the telephone was used as a tool for the categorisation of hearing through the British Post Office's nationalised telephone system. Utilising underused sources from BT Archives, Chapter 3 argues that the Post Office functioned as an arbitrator of both hearing loss and hearing aids and demonstrates that the Post Office's standard of hearing was set by a machine called the artificial ear, which used data from just ten 'normal' male ears, and elevated enduring thresholds of hearing in the fledgling field of audiometry. However, its standardisation of 'normal' hearing and devices to correct 'abnormal' hearing did not always correlate with the needs and experiences of its users. Indeed, the focus of Chapters 4, 'The audiometer and the medicalisation of hearing loss', is on how the standard of normal hearing for telephony use failed to correlate with the experience of people with hearing loss in the interwar years and argues that this led to the eventual failure of the Post Office's hearing assistive technologies. The narrative then shifts back in Chapter 5, 'The spirometer and the normal subjects', to consider processes of standardisation. The MRC's interest in normal functioning is recovered through archival sources from The National Archives, and it weaves through all these chapters, with its focus on objective anthropometric standards situated within the interwar context of heightened awareness of disability and concern about national fitness.

The MRC's remit of mechanical objectivity is thus further developed in the second half of the book, which is concerned with breathing. In Chapter 5 we return to the late nineteenth century with a detailed exploration of the initial uses of spirometric data and the development of relevant reference classes. 
To combat the difficulty of measuring breathlessness and the impossibility of making direct measurements of lung capacity, the surrogate measurement of vital capacity was developed and measured with spirometers. However, the attempt to standardise the parameters of normal breathing has been complicated by the drive to categorise the social groups that should represent the standard of normal breathing for that particular group. Thus, attempts to accurately measure and scale breathing through the spirometer were complicated by the need to first define the measure for normal breathing; there can be no abnormal without an initial definition for the normal. However, recurring questions over whether the parameters of normal breathing were universal or varied between groups marked all such attempts: normal breathing for whom? Embodied knowledge is also central to this chapter, which looks at the MRC's use of spirometry in the 1936-45 investigation of pneumoconiosis in south Wales. The chapter again focuses on the subjects used to set the standards of normalcy. I reveal that the spirometric data sets used a normal standard set by apparently healthy miners rather than a non-mining control group, thus taking its measure of normalcy from a population in which abnormality was already apparent. Spirometer tests were used as a crucial marker of the presence of respiratory disease which could not be made visible through X-rays. Thus, my focus is on the historical attempts to correlate subjective reports of breathlessness with an objective quantifiable measurement as a way to adjudicate, scale and compensate respiratory disability. By examining the history of measuring lung function in British miners, we see that the threshold for normal lung function was taken from a baseline measurement of other miners, rather than a normal comparison group. This meant that miners who felt their respiratory health to be diminished could be dismissed as healthy by apparently objective instruments. Such cases are revealed in trade union records held by the South Wales Miners' Library, Bristol University's Special Collections and Swansea University's Richard Burton Archives. Thus, central to this book is consideration of disputed disability in compensation cases focused on hearing loss and breathlessness.

The attempt to create data on such an intimate life experience is characteristic of the tension between embodied knowledge and scientific knowledge. This tension is explored throughout this book but is particularly concentrated in Chapter 6, 'The respirator and the mechanisation of normal breathing', which explores how issues pertaining to the experience of the patient were utilised in the development of resuscitation technologies. Chapter 6 thus moves to a consideration of user involvement in developing early mechanical respirators. The focus both here and in Chapter 3 is on the ways that personal bodily knowledge has been commodified and utilised in assistive technology. Tracing the 
origins of assistive breathing technologies design, with focus on engagement and co-production with users, allows for exploration of the conflict between assistive technology and lived experience. Rejection of assistive technology seen as stigmatising or inappropriate is an ongoing problem. Such assistive technology represents a twofold problem for users, in that it not only makes an invisible disability visible to the public but also makes the illness more visible to themselves. By exploring how patients have incorporated medical technology into their lives, this chapter will illuminate the dissimilitude between the engineering of assistive technology and the needs and wants of users.

The quantification of the body has resulted in the privileging of mechanical authority over subjective experience for explicitly political ends. The literal process of encoding biostatistics into machines has been used to create standard norms for specific groups of people. Through this process, the classifications used in creating these standards became invisible and appeared as natural divisions, as machines like the spirometer or the audiometer and the data they generated were venerated as objective and authoritative. In making the invisible visible and making the personal visible we are led to situations where objective measures do not correlate with lived experience. When measurement instruments are trusted over testimony in order to deny compensation, the lived experience of the disabled is denied, and it is this that represents mechanical epistemic injustice.

At its heart, this book is about resistance to standardisation and categorisation. It is a story about individual experience and its resistance to easy quantification. By studying historical attempts to measure disability, we can recover the lives and the voices of those individuals who have not been easily categorised.

\section{Notes}

1 See Nuttall, F. W., 'Body Mass Index: Obesity, BMIT, and Health: A Critical Review', Nutrition Today, 50:3 (2015), 117-128, and Gay, R., Hunger: A Memoir of (My) Body (London: HarperCollins, 2007).

2 For that, look to Brueggemann, B. J., Lend Me Your Ear: Rhetorical Constructions of Deafness (Washington, DC: Gallaudet University Press, 1999) and Berger, K. W., The Hearing Aid: Its Operation and Development (Livonia, MI: National Hearing Aid Society, 1970) for the former, and see the introduction to Braun, L., Breathing Race into the Machine: The Surprising Career of the Spirometer from Plantation to Genetics (Minneapolis: University of Minnesota Press, 2014) and Spriggs, E. A., 'The History of Spirometry', British Journal of Diseases of the Chest, 72 (1978), 165-180, for the latter.

3 This is in reference to a song, 'A Hymn to Him', delivered by the character Professor Henry Higgins in the 1964 film My Fair Lady which includes the immortal line 
'Why can't a woman be more like a man?'. See Perez, C. C., Invisible Women: Exposing Data Bias in a World Designed for Men (London: Chatto \& Windus, 2019), pp. 122-123. I love the film and recommend watching it to see Higgins playing with all sorts of technologies related to oralism: tuning forks, universal speech charts, a manometer flame, Edison phonographs and, of course, lots of lovely candlestickstyle telephones. (Alexander Melville Bell was mentioned in George Bernard Shaw's original preface to Pygmalion, though the inspiration for Higgins is normally identified as Professor Daniel Jones of UCL.)

4 Perez, Invisible Women, p. 186.

5 Ibid.

6 Epstein, S., 'Bodily Differences and Collective Identities: The Politics of Gender and Race in Biomedical Research in the United States', Body and Society 10:2/3 (2004), 183-203, p. 186.

7 Perez, Invisible Women, p. 202. I should note here that Perez advocates for increased sex-disaggregated data and more scientific research on sex differences.

8 Epstein, S., Inclusion: The Politics of Difference in Medical Research (Chicago: University of Chicago Press, 2007), p. 33.

9 In her nuanced and historically aware book, Saini reminds us that 'as science enters this new era, scientists need to be careful. Research into sex differences has an ugly and dangerous history.' Saini, A., Inferior: The True Power of Women and the Science that Shows It (London: HarperCollins, 2017), p. 64.

10 Such as between adults and children. See Virdi, J., and McGuire, C., 'Phyllis M. Tookey Kerridge and the Science of Audiometric Standardisation in Britain', British Journal for the History of Science, 51:1 (2018), 123-146.

11 Shim, J. K., Heart-Sick: The Politics of Risk, Inequality, and Heart Disease (New York: New York University Press, 2014).

12 Davis, L. J., Enforcing Normalcy: Disability, Deafness, and the Body (London: Verso, 1995), p. 67.

13 Ibid., p. 24.

14 The telephone is often described as the most lucrative patent ever.

15 Campbell-Smith, D., Masters of the Post: The Authorised History of the Royal Mail (London: Penguin Books, 2011), p. 193.

16 Daston, L., and Galison, P., Objectivity (New York: Zone Books, 2007), p. 34.

17 Ibid., p. 125.

18 Li, X., and Mills, M., 'Vocal Features: From Voice Identification to Speech Recognition by Machine', Technology and Culture, 60:2 (2019), p. 151.

19 Jewson, N. F., 'The Disappearance of the Sick Man from Medical Cosmology, 1770-1870', Sociology, 10:2 (1976), 225-244.

20 Armstrong, D., 'The Rise of Surveillance Medicine', Sociology of Health and Illness, 17:3 (1995), 393-404, p. 395.

21 Goldberg, D. S., 'Pain, Objectivity and History: Understanding Pain Stigma', Medical Humanities, 42 (2017), 238-243, p. 240.

22 Daston and Galison, Objectivity, p. 125. 
23 Gooday, G., The Morals of Measurement: Accuracy, Irony, and Trust in Late Victorian Electrical Practice (Cambridge: Cambridge University Press, 2004). p. 68.

24 Stone, D., Breeding Superman: Nietzsche, Race and Eugenics in Edwardian and Interwar Britain (Liverpool: Liverpool University Press, 2002), p. 7.

25 Petty, C., 'Primary Research and Public Health: The Prioritization of Nutrition Research in Interwar Britain', in J. Austoker and L. Bryder (eds), Historical Perspectives on the Role of the MRC: Essays in the History of the Medical Research Council of the United Kingdom and Its Predecessor, the Medical Research Committee, 1913-1953 (Oxford: Oxford University Press, 1989), pp. 83-108, p. 83.

26 Stone, Breeding Superman, p. 116.

27 Baynton, D. C., Defectives in the Land: Disability and Immigration in the Age of Eugenics (Chicago: Chicago University Press, 2016), p. 2.

28 Ibid.

29 Ibid., p. 4.

30 Prescott, H. M., 'Using the Student Body: College and University Students as Research Subjects in the United States during the Twentieth Century', Journal of the History of Medicine and Allied Sciences, 57:1 (2002), 3-38, p. 14.

31 Kudlick, C., 'Disability History: Why We Need Another "Other"', American Historical Review, 108:3 (2003), 763-793, p. 764.

32 Ibid., p. 765.

33 For a detailed account of the controversies around Bell's invention and the contenders for the role of inventor of the telephone see Shulman, S., The Telephone Gambit: Chasing Alexander Graham Bell's Secret (New York: Norton, 2008).

34 Lane, H., When the Mind Hears: A History of the Deaf (New York: Random House, 1984), p. 352. Recently, the Science and Technology Museum of Canada recreated this experiment (opting for 3D printing and silicone rather than human flesh).

35 Brueggemann, Lend Me Your Ear, p. 111.

36 Lane, When the Mind Hears, p. 345.

37 Sacks, O., Seeing Voices: A Journey into the World of the Deaf (Berkeley and Los Angeles: University of California Press, 1989), p. 152 (at n. 162, p. 151).

38 See for example: Gooday, G., and Sayer, K., Managing the Experience of Hearing Loss in Britain, 1830-1930 (London: Palgrave Macmillan, 2017); Lane, When the Mind Hears; and Padden, C. and Humphries, T., Inside Deaf Culture (Cambridge, MA: Harvard University Press, 2005).

39 Hutchinson, I., 'Oralism: A Sign of the Times? The Contest for Deaf Communication in Education Provision in Late Nineteenth-Century Scotland', European Review of History, 14:4 (2007), 481-501, p. 484.

40 Eriksson, P., The History of Deaf People: A Source Book (Orebro: Daufr, 1991), p. 18 and p. 28.

41 Baynton, D. C., " "Savages and Deaf Mutes": Evolutionary Theory and the Campaign against Sign Language in the Nineteenth Century', in J. V. van Cleve (ed.), Deaf History Unveiled (Washington, DC: Gallaudet University Press, 1993), pp. 92-112, p. 108. 
42 See, for example, Behnke, E., and Browne, L., Voice, Song, and Speech: A Practical Guide for Singers and Speakers (London: Sampson Low, Marston and Company, 1891).

43 Sterne, J., The Audible Past: Cultural Origins of Sound Reproduction (Durham, NC: Duke University Press, 2003), p. 41.

44 Tallents, S., Post Office Publicity (Post Office Green Paper No. 8) (London: His Majesty's Stationery Office, 1935), British Telecom Archives, London (BTA), TCB 350/8.

45 Campbell-Smith, Masters of the Post, pp. 270-271.

46 Agar, J., Constant Touch: A Global History of the Mobile Phone (Cambridge: Icon Books, 2003), p. 395.

47 Glynn, S., and Oxborrow, J., Interwar Britain: A Social and Economic History (London: George Allen \& Unwin, 1976), p. 24.

48 Bryder, L., 'Tuberculosis and the MRC', in J. Austoker and L. Bryder (eds), Historical Perspectives on the Role of the MRC: Essays in the History of the Medical Research Council of the United Kingdom and Its Predecessor, the Medical Research Committee, 1913-1953 (Oxford: Oxford University Press, 1989), pp. 1-21, p. 1.

49 Ibid., p. 2.

50 Austoker, J., and Bryder, L., 'The National Institute for Medical Research and Related Activities of the MRC', in J. Austoker and L. Bryder (eds), Historical Perspectives on the Role of the MRC: Essays in the History of the Medical Research Council of the United Kingdom and Its Predecessor, the Medical Research Committee, 19131953 (Oxford: Oxford University Press, 1989), pp. 35-57, p. 50.

51 Bryder, 'Tuberculosis and the MRC', p. 8.

52 Valier, H., and Timmermanns, C., 'Clinical Trials and the Reorganization of Medical Research in Post-Second World War Britain', Medical History, 52 (2008), 493510 .

53 Austoker and Bryder, 'The National Institute for Medical Research', p. 53.

54 Keating, C., Smoking Kills: The Revolutionary Life of Richard Doll (Oxford: Signal Books, 2014), p. 57.

55 Ibid., p. 17 and p. 62.

56 Epstein, Inclusion, p. 48.

57 Kelvin, W. T., 'Electrical Units of Measurement: A Lecture Delivered at the Institution of Civil Engineers on May 3, 1883; Being One of a Series of Six Lectures on "The Practical Applications of Electricity", Nature Series: Popular Lectures and Addresses (London: Macmillan and Co., 1889), p. 73. The Kelvin scale is used to measure absolute temperature. It is useful because it includes no negative numbers, absolute zero is its fixed point.

58 Gooday, The Morals of Measurement, Preface, p. 17.

59 Ibid., p. 21 and p. 33.

60 Cryle, P., and Stephens, E., Normality: A Critical Genealogy (Chicago: University of Chicago Press). 
61 Eknoyan, G., 'Historical Note: Adolphe Quetelet (1796-1874) - The Average Man and the Indices of Obesity', Nephrology Dialysis Transplantation, 23:1 (2008), 47-51.

62 Rasmussen, N., 'Downsizing Obesity: On Ancel Keys, the Origins of BMI, and the Neglect of Excess Weight as a Health Hazard in the United States from the 1950s to 1970s', The History of the Behavioral Sciences, 55:4 (2019), 299-318.

63 Stokes, M., “"What Does fMRI Measure?” Brain Metrics: How Measuring Brain Biology Can Explain the Phenomena of Mind', Nature Blog, 16 May 2019. www. nature.com/scitable/blog/brain-metrics/what_does_fmri_measure/. Accessed May 2019.

64 Waring, M., If Women Counted: A New Feminist Economics (London: Macmillan, 1989).

65 The NHS website highlights the fact that breastfeeding reduces the risk of infant infections, which means a reduction in hospital visits. See www.nhs.uk/conditions/pregnancy-and-baby/benefits-breastfeeding/. Accessed July 2019.

66 BBC Radio 4, 'The Real Gender Pay Gap', Analysis, 10 June 2019. www.bbc.co.uk/ programmes/m0005t3n?fbclid=IwAR1ESVFYDqjKurDDbkxU4eROmOdmPY3nooXJO15KqSkldX2Xc8Kcl7XDQtE. Accessed June 2019.

67 Professor Diane Coyle of Manchester University Economics Department, quoted in Perez, Invisible Women, pp. 239-240.

68 Macnaughton, J., 'Numbers, Scales, and Qualitative Research', The Lancet, 347:9008 (1996), 1099-1100, p. 1099.

69 Biss, E., 'The Pain Scale', in J. E. Sullivan III (ed.), Ways of Reading: An Anthology for Writers (Boston and New York: Bedford/St. Martins, 2011), pp. 171-182, p. 178.

70 Bourke, J., The Story of Pain: From Prayer to Painkillers (Oxford: Oxford University Press, 2014).

71 Norman, A., Ask Me about My Uterus (New York: Nation Books, 2018), Kindle version location 252 of 4573.

72 Canguilhem, G., The Normal and the Pathological (Cambridge, MA: Zone Books, 3rd edn, 1991).

73 Ibid., p. 154.

74 Cryle and Stephens, Normality.

75 Stephens, E., 'The Object of Normality: The Search for Norma Competition', Queer Objects Symposium Paper, October 2014. www.academia.edu/8893077/ The_Object_of_Normality_The_Search_for_Norma_Competition. Accessed May 2019.

76 Rose, T., The End of Average (London: Allen Lane, 2016), p. 7.

77 Ibid., p. 8.

78 Weber, R. N., 'Manufacturing Gender in Commercial and Military Cockpit Design', Science, Technology, and Human Values, 22:2 (1997), 235-253.

79 Ibid., p. 238.

80 Stephens, 'The Object of Normality'.

81 Prescott, 'Using the Student Body', p. 16.

82 Ibid., p. 30.

83 Ibid., p. 38 . 
84 Gotzsche, P. C., Deadly Medicine and Organised Crime: How Big Pharma has Corrupted Healthcare (London: Radcliffe Publishing, 2013).

85 Partly as a result of this activism, the Americans with Disabilities Act (1990) and the Disability Discrimination Act (1995) in Britain were enacted. See Gerber, D. A., 'Introduction: Finding Disabled Veterans in History', in D. A. Gerber (ed.), Disabled Veterans in History (Ann Arbor: University of Michigan Press, 2000), pp. 152.

86 Ibid.

87 See: Lane, When the Mind Hears; Padden and Humphries, Inside Deaf Culture; Sacks, Seeing Voices; Eriksson, The History of Deaf People; Baynton, "'Savages and Deaf Mutes"'; and Branson, J., and Miller, D., Damned for Their Difference: The Cultural Construction of Deaf People as Disabled (Washington, DC: Gallaudet University Press, 2002).

88 This category was explored for the first time in a recent monograph, Gooday and Sayer, Managing the Experience of Hearing Loss.

89 Assistive technology such as hearing aids and ambulatory oxygen. See McGuire, C., and Carel, H., 'The Visible and the Invisible: Disability, Assistive Technology, and Stigma', in D. T. Wasserman and A. Cureton (eds), The Oxford Handbook of Philosophy and Disability (Oxford: Oxford University Press, 2019), pp. 598-615.

90 For discussion of the difficulty of distinguishing between somatic and physiological breathlessness see Williams, T., and Carel, H., 'Breathlessness: From Bodily Symptom to Existential Experience', in K. Aho (ed.), Existential Medicine: Essays on Health and Illness (London: Rowman \& Littlefield, 2018), pp. 145-159, p. 147. For discussion of how individual psychology and past experiences affect neurological processing of breathlessness see Faull, O. K., Hayen, A., and Pattinson, K. T. S., 'Breathlessness and the Body: Neuroimaging Clues for the Inferential Leap', Cortex, 95 (2017), 211-221. For personal perspective and more on how we use our whole body to process sounds see Bathurst, B., Sound: Stories of Hearing Lost and Found (London: Profile Books, 2017).

91 Williams and Carel, 'Breathlessness', p. 152.

92 Kudlick, 'Disability History', p. 765.

93 Hughes, B., and Paterson, K., 'The Social Model of Disability and the Disappearing Body: Towards a Sociology of Impairment', Disability and Society, 12:3 (1997), 324-340, p. 326.

94 For a review of the divergences between medical history and disability history in the USA see Linker, B., 'On the Borderland of Medical and Disability History: A Study of the Fields', Bulletin of the History of Medicine, 87:4 (2013), 499-535.

95 For a discussion of the history of the medical and social model of disability see Shakespeare, T., 'The Social Model of Disability', in L. J. Davis (ed.), The Disability Studies Reader (London: Routledge, 4th edn, 2013), pp. 214-221. For a discussion of the problems of the social model for historians see Anderson, J., War, Disability and Rehabilitation in Britain (Manchester: Manchester University Press, 2011), pp. 5-6. 
96 For a comprehensive overview of these criticisms see Shakespeare, T., Disability Rights and Wrongs Revisited (London: Routledge, 2nd edn, 2013).

97 This has also made the social model incompatible with disability history focused on prostheses, etc. which one could argue were a very important part of historical actors' lives. Shakespeare, 'The Social Model of Disability', p. 221.

98 Mjolstad, B. P., Kirkengen, A. L., Getz, L., and Hetlevik, I., 'What Do GPs Actually Know about Their Patients as Persons?', European Journal for Person Centered Healthcare, 1:1 (2012), 149-160.

99 Faull et al., 'Breathlessness and the Body'.

100 See Booth, S., Chin, C., and Spathis, A., 'The Brain and Breathlessness: Understanding and Disseminating a Palliative Care Approach', Palliative Medicine, 29:5 (2015), 396-398, and Spathis, A., Booth, S., Moffat, C., Hurst, R., et al., 'The Breathing, Thinking, Functioning Clinical Model: A Proposal to Facilitate Evidence-Based Breathlessness Management in Chronic Respiratory Illness', NPJ Primary Care Respiratory Medicine, 27:1 (2017), 1-6.

101 Faull, O. K., Marlow, L., Finnegan, S. L., and Pattinson, K. T. S., 'Chronic Breathlessness: Re-Thinking the Symptom', European Respiratory Journal, 51:1 (2018), 1-5.

102 Herzog, M., Sucec, J., Diest, I. V., Chevinesse, C., et al., 'Observing Dyspnoea in Others Elicits Dyspnoea, Negative Affect and Brain Responses', European Respiratory Journal, 51:4 (2018), 1-10.

103 See www.lifeofbreath.org and Macnaughton, J., and Carel, H., 'Breathing and Breathlessness in Clinic and Culture: Using Critical Medical Humanities to Bridge an Epistemic Gap', in A. Whitehead and A. Woods (gen. eds), The Edinburgh Companion to the Critical Medical Humanities (Edinburgh: Edinburgh University Press, 2016), pp. 294-309.

104 Carel, H., Macnaughton, J., and Dodd, J., 'Invisible Suffering: Breathlessness in and beyond the Clinic', The Lancet: Respiratory Medicine, 3:4 (2015), 278-279, p. 278.

105 Nicholls, D., 'Breathlessness: A Qualitative Model of Meaning', Physiotherapy, 86:1 (2000), 23-27, p. 23.

106 Warman, C., 'From Pre-Normal to Abnormal: The Emergence of a Concept in Late Eighteenth Century France', Psychology \& Sexuality, 1:3 (2010), 200-213, p. 206.

107 Ibid.

108 Eknoyan, 'Historical Note'.

109 Ibid.

110 Neff, G., and Nafus, D., Self-Tracking (Cambridge, MA: MIT Press, 2016), p. 39.

111 Eknoyan, 'Historical Note.'

112 Gould, S. J., The Mismeasure of Man (New York: Norton, 2nd edn, 1996), p. 107.

113 Braun, Breathing Race into the Machine, p. 92.

114 It feels important to note here that I am a woman from the north-east of Scotland and that I thoroughly disagree with this assessment.

115 Gould, The Mismeasure of Man, pp. 105-106. 
116 Stone, Breeding Superman, p. 105.

117 Gould, The Mismeasure of Man, p. 31.

118 Flynn, J. R., What is Intelligence? (Cambridge: Cambridge University Press, 2007), p. 8.

119 Gould, The Mismeasure of Man, p. 23.

120 Lewis, J. E., DeGusta, D., Meyer, M. R., Monge, J. M., et al., 'Correction: The Mismeasure of Science: Stephen Jay Gould versus Samuel George Morton on Skulls and Bias', PLoS Biology, 9:7 (2011), 1-6.

121 Hacking, I., 'Biopower and the Avalanche of Printed Numbers', Humanities in Society, 5 (1982), 279-295.

122 Porter, T. M., 'Measurement, Objectivity, and Trust', Measurement: Interdisciplinary Research and Perspectives, 1:4 (2003), 241-255, p. 246.

123 Bouk, D., How Our Days Became Numbered: Risk and the Rise of the Statistical Individual (Chicago: University of Chicago Press, 2015).

124 Ibid., Preface, p. 28.

125 Porter, 'Measurement, Objectivity, and Trust', p. 250.

126 Porter, T. M., 'Objectivity as Standardization: The Rhetoric of Impersonality in Measurement, Statistics, and Cost-Benefit Analysis', in A. Megill (ed.), Rethinking Objectivity (Durham, NC and London: Duke University Press, 1994), pp. 197-237, p. 216.

127 Epstein, Inclusion, p. 60.

128 Kohrman, M., 'Why Am I Not Disabled? Making State Subjects, Making Statistics in Post-Mao China', Medical Anthropology Quarterly, 17:1 (2003), 5-24, p. 6.

129 Foucault, M., The History of Sexuality: Volume One (London: Penguin Books, 1976), p. 140.

130 Ibid., p. 139.

131 Hacking, 'Biopower and the Avalanche of Printed Numbers'.

132 Braun, Breathing Race into the Machine.

133 Heggie, V., 'Testing Sex and Gender in Sports: Reinventing, Reimagining and Reconstructing Histories', Endeavour, 34:4 (2010), 157-163.

134 Ibid., p. 157.

135 Stone, Breeding Superman, p. 99.

136 This is the central thesis of Baynton, Defectives in the Land. The quoted terminology is from primary sources used in the chapter 'The "Lethal Chamber" in Eugenic Thought', in Stone, Breeding Superman, although there is no explicit discussion in Stone's book of disability. 